\title{
Socioeconomic status in Danish transgender persons: a nationwide register-based cohort study
}

\author{
Dorte Glintborg@1,2,*, Katrine Hass Rubin ${ }^{3, *}$, Simon Bang Mohr Kristensen ${ }^{3}, \emptyset$ jvind Lidegaard $^{4,5}$, Guy T'Sjoen ${ }^{6}$ \\ Aisa Burgwal ${ }^{6}$, Malene Hilden ${ }^{4,7}$ and Marianne Skovsager Andersen ${ }^{1,2}$ \\ ${ }^{1}$ Department of Endocrinology, Odense University Hospital, Odense, Denmark \\ ${ }^{2}$ Institute of Clinical Research, University of Southern Denmark, Odense, Denmark \\ ${ }^{3}$ Open Patient Data Explorative Network, Department of Clinical Research, University of Southern Denmark and Odense University Hospital, \\ Odense, Denmark \\ ${ }^{4}$ Department of Gynecology, Rigshospitalet, University of Copenhagen, Copenhagen, Denmark \\ ${ }^{5}$ Department of Clinical Medicine, University of Copenhagen, Copenhagen, Denmark \\ ${ }^{6}$ Department of Endocrinology and Center for Sexology and Gender, Ghent University Hospital, Gent, Belgium \\ ${ }^{7}$ Centre for Gender Identity, Department of Gynaecology, Rigshospitalet, University of Copenhagen, Copenhagen, Denmark
}

Correspondence should be addressed to D Glintborg: dorte.glintborg@rsyd.dk

*(D Glintborg and K H Rubin contributed equally to this work as first authors)

\begin{abstract}
Background: Gender dysphoria could be associated with low socioeconomic status (SES). SES could be modified by age, ethnic background, and medical morbidity.

Aim: To determine SES in a national study population including transgender persons in Denmark.

Methods: National register-based cohort study in Danish transgender persons and agematched controls. The transgender study cohort included persons with ICD-10 diagnosis code of 'gender identity disorder' and/or persons with legal sex change and persons who fulfiled the inclusion criteria during 2000-2018. The main outcome measure was SES including personal income, occupational status, and education.

Results: The cohort included 2770 transgender persons and 27,700 controls. In the transgender study cohort, 1437 were assigned male at birth (AMAB), median age (interquartile range, IQR) 26.0 (17.3) years, and 1333 were assigned female at birth (AFAB), median age 22.5 (10.3) years. Adjusting for age and sex, the relative risk ratio (RRR) of low vs high personal income was $5.6(95 \% \mathrm{Cl}: 4.9 ; 6.3)$ in transgender persons compared to controls. The RRR of low vs high income was $6.9(5.8 ; 8.3)$ in persons AMAB compared to control males and $4.7(3.9 ; 5.6)$ in persons AFAB compared to control females. The RRR of low vs high income was $3.7(3.2 ; 4.3)$ in transgender persons of Danish origin compared to controls. The Charlson comorbidity index was comparable in transgender persons vs controls.

Conclusions: Being transgender was negatively associated with SES. In transgender persons, the risk of low vs high income could be more pronounced in transgender persons of foreign origin.
\end{abstract}

\author{
Key Words \\ - transgender \\ - gender identity \\ - gender incongruence \\ - register-based \\ - socioeconomic status \\ - ethnicity \\ - nationwide \\ - Charlson comorbidity \\ index
}

https://ec.bioscientifica.com

https://doi.org/10.1530/EC-21-0119 (c) 2021 The authors Published by Bioscientifica Ltd

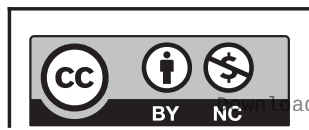

This work is licensed under a Creative Commons Attribution-NonCommercial 4.0 International License. ded from Bioscientifica.com at 04/26/2023 09:59:33AM
Endocrine Connections (2021) 10, 1155-1166 


\section{Introduction}

The term transgender is an umbrella term to group individuals whose gender identity differs from the assigned sex at birth. Transgender females are assigned male at birth (AMAB) but identified as females and transgender males are assigned female at birth (AFAB) but identified as males (1). The number of transgender individuals in Denmark is unknown. Recent European studies reported that $0.7-1.1 \%$ of $\mathrm{AMAB}$ and $0.6-0.8 \%$ of AFAB reported incongruent gender identity (1), which would correspond to 50,000 Danish individuals in a total population of 5.8 million inhabitants. In Denmark, assessment and medical or surgical treatment of adult transgender persons take place at three centres located in Copenhagen, Odense, and Aalborg. Persons $<18$ years are evaluated by a specialist team in Copenhagen. In Denmark, general practitioners refer transgender persons to a gender team. At present, around 800 new referrals take place each year with an increasing number. There is no individual cost for consultations with psychologists and medical doctors as all expenses are covered by the Danish public health care system. Therefore, in theory, all transgender persons have equal access to the health care system in Denmark. However, the general medicine support system in Denmark reimburses only a percentage of the price for gender-affirming hormonal treatment.

Quality of life is impaired in many persons with incongruent gender identity $(2,3)$ and the risk of depression (4) and suicide (5) is increased. In many societies, transgender persons are at high risk of minority stress where poor physical and/or mental health of sexual minorities can be partly explained by stress factors caused by a LGBTQ phobic culture (6). As a result, transgender persons are considered to be at high risk for poor health (7). In the general population, low socioeconomic status (SES) is an important predictor of impaired health including shorter life expectancy $(8,9)$. In transgender and nonbinary persons, low SES was associated with lower wellbeing (10), higher prevalence of health care discrimination (11), and higher suicide rates $(5,12)$. Degree of education and personal income increase with increasing age, and age could be associated with general wellbeing (10). Previous studies regarding SES in transgender cohorts examined selected sub-cohorts of transgender populations (10, $11,13)$. One previous national study in Belgium showed that a high proportion of transgender persons was employed (63\%) with no significant difference between female-to-male (FtM) and male-to-female (MtF) transgender persons (14). The study was based on data before 2010, and we are not aware of any recent study regarding SES in nationwide cohorts of transgender individuals.

In 2014, Denmark was the first European country to allow legal change of sex independently of castration due to a transgender condition. Less liberal approaches to transgender care in other countries could result in a higher immigration rate to Denmark for persons with gender dysphoria. Foreign background was negatively associated with SES and mental health in transgender study populations $(11,12)$. In addition, immigrants could have a higher rate of unemployment due to language or cultural differences, which would result in lower income. A different cultural background may increase minority stress (6). To our knowledge, the immigration pattern to a country with good access to transgender health care has not been evaluated previously.

The aim of this register-based cohort study was to compare SES in a nationwide group of transgender persons and controls based on data from Danish national registers. We also investigated SES and ethnic background in transgender persons living in Denmark.

\section{Materials and methods}

The study design was a register-based cohort study.

\section{Study population}

We aimed to include all persons with gender dysphoria according to Danish registries. The study population was formed by the identification of two cohorts of transgender persons (Fig. 1). Persons with a diagnosis code of transgender and persons with sex change identified by a change in social security number (CPR). Transgender persons should fulfil one of the inclusion criteria during the period 2000-2018 and had a valid Danish address at the time of inclusion. CPR change should occur after the age of 18 years.

\section{Exclusion criteria}

Gender dysphoria is rarely diagnosed in ageing persons (15) and we excluded individuals aged $\geq 80$ years at index date. We also excluded persons if legal sex change according to the CPR registry was reversed within 30 days.

The index date was the first time a patient fulfiled one of the inclusion criteria during the study period.

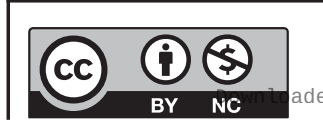

This work is licensed under a Creative Commons Attribution-NonCommercial 4.0 International License. ded from Bioscientifica.com at 04/26/2023 09:59:33AM via free access 


\section{Trans-DK OUH}

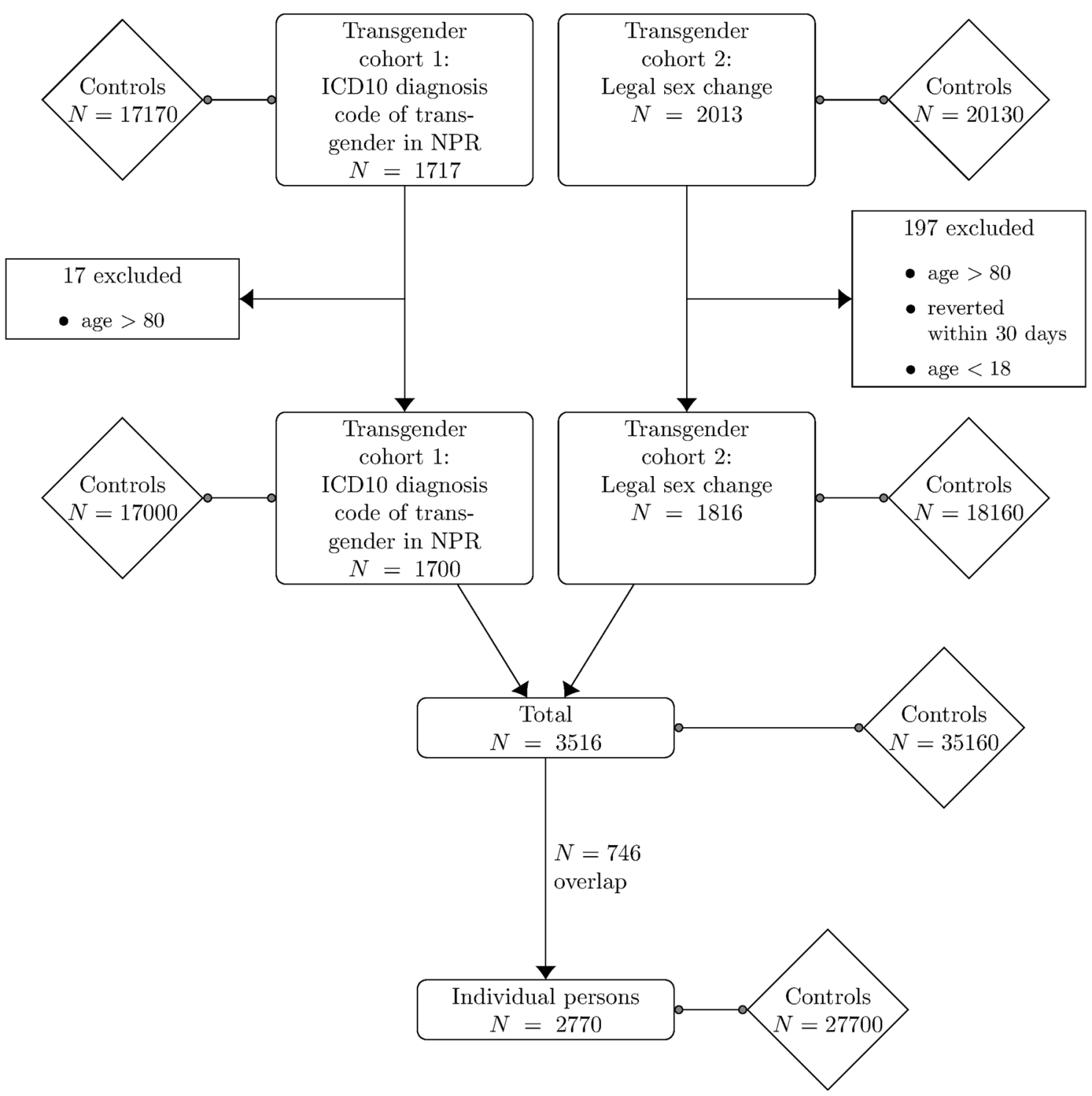

Figure 1

Flowchart of study cohort.

\section{Controls}

For each patient, we randomly drew five age-matched controls of the same sex at birth and five age-matched controls of the other sex at birth from the Danish Civil registration system (CRS) (Fig. 1). Controls were assigned the index date of their matched transgender person. The controls were born in the same year and had to be alive at the index date of their respective matched transgender person. The controls could not be included in the transgender group at the time of inclusion and could only act as a control to a single transgender person.

\section{The Danish health registries}

In Denmark, all citizens are provided with a unique CPR issued at birth or upon immigration to Denmark. The CPR is the key identifier in the Danish population-based medical records and can be used to link data from all Danish health and social care registers at an individual level $(16,17)$. Information regarding hospital contacts was included from all persons along with dates of death if applicable. We used data from the National Patient Register (NPR) (16) and CRS (17). The CRS was established in 1968 and maintains complete records of births, deaths,

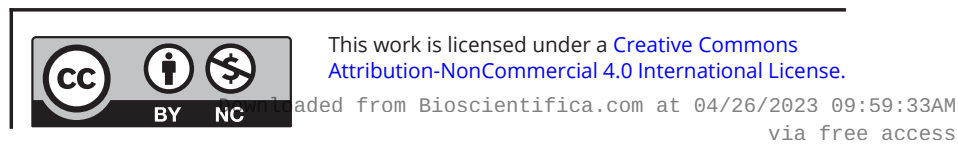


civil and emigration status. CRS contributed data on death and emigration during follow-up, civil status, and geographic origin (17).

\section{ICD-10 diagnosis codes}

The NPR contains data on all inpatient hospital contacts in Denmark since 1977 and outpatient contacts are included since 1995 (18). From 2002, NPR also includes contacts for private hospitals excluding private practice specialists and general practitioners. We extracted ICD-10 diagnosis codes of transgender from the NPR from 2000 to 2018. Until 2017, the diagnosis codes F64-F649 ('transsexual, gender identity disorder') were applied (19). The diagnosis codes DZ768E-DZ768E4 ('contact regarding gender identity condition') were introduced and applied after 2017 according to Danish legislation. We extracted diagnoses from psychiatric and somatic parts of NPR.

\section{Sex change}

We used the CRS to define sex change. The Danish CPR contains ten digits where the first six digits correspond to the birth date and the last digit indicates a person's legal sex (odd digit for males, even digit for females) (18). According to Danish law, a citizen can apply for legal sex change, which implies a change of the male or female identifier of the CPR number. Until 2014, legal change of gender could only be applied following castration due to a transgender condition. However, since 1 September 2014, persons aged > 18 years can freely apply for a legal change of sex (which implies changing the sex identifying part of the CPR number) independent of any contact to the health care system. To qualify for inclusion into the study, legal sex change should occur after the age of 18 years according to Danish law. If a CPR change implied a change in the birth date identifier of the CPR only, the case was not valid for inclusion.

\section{Definition of study parameters}

Age was calculated at the index date.

\section{Assigned sex at birth}

Assigned sex at birth was determined as the earliest recorded CPR-encoded sex. Transgender persons were divided into persons affirmed male sex at birth (AMAB) and persons assigned female sex at birth (AFAB). The CPR number is issued at birth or when immigrating to Denmark, and persons with sex change before the date of immigration would potentially be assigned a CPR number according to their sex by date of immigration.

\section{Socioeconomic status (SES)}

Variables on SES included information on personal income, occupational status, and education. Data were retrieved from Danish registers at Statistics Denmark as described below on the index year for each person.

\section{Personal income}

Personal income was extracted from the Income Statistics Register (20) and included information on the available average income after tax and interest (included salary, retirement benefits, welfare payment, remuneration, company profits, etc.). The income was categorized into tertiles (high, middle, low) using controls as the reference population: data were divided into age groups $(\leq 18,18-25$, $25-30, \ldots, 60-65,>65$ years at inclusion) and within each age group, tertiles were determined from the control group and interpolated to the group of transgender persons. Tertiles were not recalculated when performing stratified or sensitivity analyses.

\section{Occupational status (affiliation to the labour market)}

Occupational status was extracted from the Income Statistics Register (20) and divided into five categories: affiliated to labour market (employed or self-employed), education, unemployed or welfare payment, early retirement, and unknown or missing.

\section{Education}

Education was extracted from the Population Education register and included information on the highest completed education based on the International Standard Classification of Education (21). The Population Education register covers education and training completed in Denmark. Information on completed education acquired outside Denmark and information for immigrants is selfreported (if available). Education level was divided into higher education, further education (short-cycle tertiary, bachelor education or equivalent), vocational education, upper secondary school, basic school (primary), and unknown or missing. The highest completed education was extracted from the year of inclusion and all previous years from the study period.

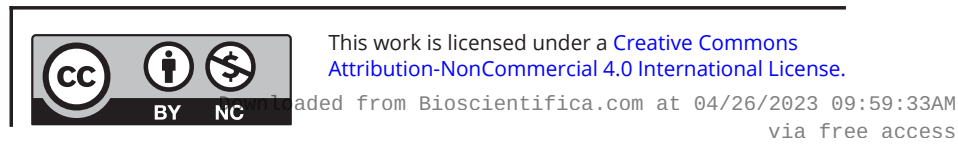




\section{Area of origin}

Area of origin was extracted from CRS (22) and divided into continents (Europe, America (North and South), Africa, Asia, Oceania, and unknown or missing).

\section{Ethnicity}

Ethnicity was extracted from the CRS (22) and divided into Danish, immigrants, descendants, and unknown or missing.

\section{Medical morbidity}

The Charlson comorbidity index is based on 19 medical conditions (myocardial infarction, congestive heart failure, peripheral vascular disease, cerebrovascular disease, dementia, chronic pulmonary disease, connective tissue disease, ulcer disease, diabetes, hemiplegia, moderate or severe renal disease, diabetes with end-organ damage, any tumour, leukaemia, lymphoma, mild liver disease, moderate or severe liver disease, metastatic solid tumour and AIDS) (23) and was calculated from the ICD-10 operationalization by Quan et al. (24). The Charlson comorbidity index was used to classify medical conditions among individuals from 5 years prior to the index date. To calculate the Charlson comorbidity index, we used information from the NPR and the score was categorized into no comorbidity ( 0 ) and $\geq 1$ comorbidity.

\section{Ethics}

The study design was an open register-based cohort study and no approval is necessary from the local Ethics committee or Institutional Review Board by Danish law. The study is approved by the Data Protection Agency and Statistics Denmark. Information regarding the study is published with Open ID: 939 https://open.rsyd.dk/ OpenProjects/openProject.jsp?openNo=939\&lang=da.

\section{Statistical analyses}

Baseline characteristics in transgender persons are presented as frequencies for categorical variables. Continuous variables are summarized as medians with interquartile range (the distance from the 25-75\% percentile). Multinomial logistic regression analyses were used to estimate relative risk ratios (RRRs) with 95\% CIs, to examine the association between transgender and SES, ethnicity, area of origin and comorbidity for transgender persons vs matched controls. Missing and unknown observations were excluded from the analyses. The RRR was reported after adjusting for matching factors: index age and sex. When adjusting for sex, cases were assigned their sex at birth while controls were assigned their sex at the time of inclusion. To account for the fact that some controls enter as cases, a cluster robust variance estimator was applied. A stratified analysis was performed splitting the case population on the sex at birth (AMAB or AFAB). Comparisons of estimates between the two strata defined by sex at birth were performed on a log-scale assuming that the strata were independent so that the standard error of the difference was given as the square root of the sum of squared strata-specific standard errors. The level for statistical significance was set to $5 \%$.

\section{Sensitivity analyses}

A sensitivity analysis was performed where persons born outside Denmark were excluded. Primary analyses were repeated in persons above age 30 years. Furthermore, primary analyses were repeated stratifying on inclusion before or after 1 January 2014. Finally, a sensitivity analysis was performed in transgender persons of Danish origin, who entered the study first due to a relevant diagnosis code (i.e. cohort 1 ).

Data management and data analyses were conducted using Stata 16 (StataCorp. 2019, Stata Statistical Software: Release 16; StataCorp LLC, College Station, TX) through a remote VPN access to Statistics Denmark with analysts blinded to the personal identities of the study subjects.

\section{Results}

\section{Study cohort}

A flowchart of the study cohort is shown in Fig. 1. The study cohort included 1717 individuals with ICD10 diagnosis code of transgender (cohort 1) and 2013 individuals with legal sex change (cohort 2). We excluded 214 individuals due to age $>80$ years, CPR change $<18$ years of age, or reverted CPR within 30 days, which left a total of 3516 persons in study cohort 1 or 2 . A total of 746 persons were included in both study cohorts, which left 2770 individual persons in the study cohort (Fig. 1). In the study cohort, 1437 (52\%) were AMAB and 1333 (48\%) were AFAB. The median age at the index date was 26.0 (17.3) years in AMAB individuals and 22.5 (10.3) years in AFAB individuals. Table 1 shows the age at the index date in the study cohort divided according to assigned sex at birth.

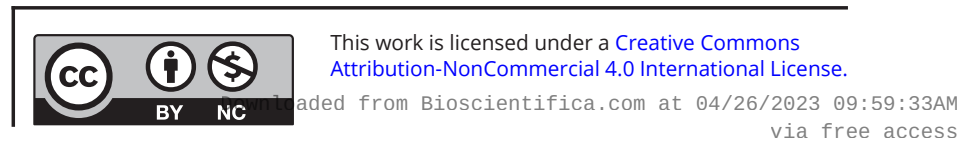


Table 1 Age distribution, diagnosis codes and legal sex change in transgender persons $(n=2770)$. Data presented as number (percentage).

\begin{tabular}{l}
\hline \\
\hline Transgender cohort 1: ICD10 diagnosis code of transgender \\
2000-2017 \\
F640 transsexualism \\
F642 gender identity disorder of childhood \\
F648 other gender identity disorders \\
F649 gender identity disorder, unspecified \\
Total, $2000-2017$ \\
2017-2018 \\
DZ768E contact regarding gender identity \\
DZ768E1 contact regarding transgender identity \\
DZ768E2-3 contact regarding gender identity in \\
childhood and other gender identity conditions \\
DZ768E4 contact regarding gender identity condition, \\
unspecified \\
Total, 2017-2018 \\
Total, transgender cohort 1 \\
Transgender cohort 2: legal sex change \\
21 CPR changes \\
Unique individuals
\end{tabular}

\begin{tabular}{l} 
Total, $\boldsymbol{n}(\%)$ \\
\hline \\
$270(24.7)$ \\
$44(4.0)$ \\
$29(2.7)$ \\
$750(68.6)$ \\
1093
\end{tabular}

$n(\%)$

$80(13.2)$

$14(2.3)$

159 (26.1)

25 (4.1)

$16(2.6)$

$409(67.2)$

609

455 (75.0)

$27(10.4)$

$34(13.1)$

$7(2.7)$
36.6 (24.5)
$8.9(8.2)$
33.4 (21.3)
26.5 (22.2)
$28.2(23.4)$

$22.7(13.8)$

$21.8(15.3)$

$15.6(28.4)$

607

1700

$192(73.8)$

$23.2(11.0)$

260

869

1816

2770

$22.8(12.6)$

$26.1(21.3)$

913

1437

$26.9(15.3)$

$26.0(17.3)$

\begin{tabular}{c}
$111(22.9)$ \\
$19(3.9)$ \\
$13(2.7)$ \\
$341(70.5)$ \\
484 \\
$31(8.9)$ \\
$46(13.3)$ \\
$7(2.0)$ \\
$263(75.8)$ \\
347 \\
831 \\
903 \\
1333 \\
\hline
\end{tabular}

$19.9(9.4)$

$14.3(7.8)$

$18.9(3.1)$

$21.2(11.4)$

20.8 (10.4)

$A F A B$, assigned female at birth; $A M A B$, assigned male at birth; CPR, social security number; IQR, inter-quartile range.

\section{Transgender persons vs controls}

Socioeconomic status (SES) in the study cohort of transgender persons compared to age-matched controls is shown in Table 2 . The relative risk ratio (RRR) for low vs high personal income was $5.6(4.9 ; 6.3)$ in transgender persons compared to controls. The RRR of being unemployed or on welfare vs employed was $4.4(3.8 ; 5.1)$ in transgender persons compared to controls and the RRR for early retirement vs employed was $4.3(3.5 ; 5.3)$. The RRR for having primary school as the highest level of education vs higher education was $3.7(2.1 ; 6.3)$ in transgender persons compared to controls, but education status was unknown or missing in $75.7 \%$ of the transgender study cohort.

Ethnic status was Danish or descendant in 58.2\% transgender persons and $89.0 \%$ in controls. Immigrants in the transgender cohort most often originated from Europe, Asia and Oceania.

The RRR for having a Charlson comorbidity index $\geq 1$ was $0.7(0.6 ; 1.0)$ in transgender persons compared to controls.

\section{AMAB transgender persons vs controls}

SES in AMAB transgender persons was compared to agematched control males and control females (Table 3). The RRR for low vs high personal income was 6.9 (5.8; 8.3) for transgender persons compared to control males and 4.7 ( $3.9 ; 5.6)$ compared to control females. The RRR for being unemployed or on welfare vs employed was 6.0
(4.9; 7.4) in transgender persons compared to control males and $3.8(3.1 ; 4.6)$ compared to control females. The prevalence of immigrants was $36.7 \%$ and the area of origin was most often Europe, Asia and Oceania. The RRR of Charlson comorbidity index $\geq 1$ was $0.5(0.3 ; 0.8)$ in AMAB transgender persons compared to control females and similar to control males: $0.7(0.5 ; 1.1)$.

\section{AFAB transgender persons vs controls}

AFAB transgender persons were compared to age-matched control females and control males (Table 4). The RRR for low vs high personal income was $4.7(3.9 ; 5.6)$ compared to control females and $5.9(4.9 ; 7.1)$ compared to control males. The RRR for unemployment or welfare vs employed was $2.6(2.1 ; 3.4)$ compared to control females and 5.1 (4.0; 6.5) compared to control males. Immigrants had a prevalence of $32.0 \%$ and most often originated from Europe. Estimates of RRR of Charlson comorbidity index $\geq 1$ in AFAB transgender persons were lower than 1 compared to control females $(0.8(0.5 ; 1.3))$ and to control males $(0.9(0.6 ; 1.4))$, but this difference was not significant.

\section{$A M A B$ vs AFAB transgender persons}

The relative difference $R_{R} R_{A M A B} / R R R_{A F A B}$ for low vs high income was $1.18(0.91 ; 1.52)$ when comparing to male controls and $1.01(0.78 ; 1.30)$ comparing to female controls.

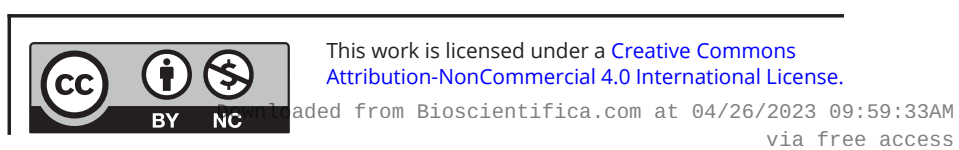


Table 2 Socioeconomic status and Charlson comorbidity index in transgender persons (TransDK, $n=2770$ ) vs controls $(n=27,700)$. Data presented as number (percentage).

\begin{tabular}{|c|c|c|c|}
\hline & Trans, $n(\%)$ & Control, $n(\%)$ & Trans vs controls, RRR ( $\mathrm{Cl} 95 \%)$ adjusted \\
\hline \multicolumn{4}{|l|}{ Personal income } \\
\hline High & $306(11.0)$ & $9223(33.3)$ & 1 \\
\hline Middle & $610(22.0)$ & $9225(33.3)$ & $2.0(1.8 ; 2.3)$ \\
\hline Low & $1672(60.4)$ & $9230(33.3)$ & $5.6(4.9 ; 6.3)$ \\
\hline Unknown/missing & $182(6.6)$ & $22(0.1)$ & - \\
\hline \multicolumn{4}{|l|}{ Occupational status } \\
\hline Affiliated to labour market & $585(21.1)$ & $12,718(45.9)$ & 1 \\
\hline Under education & $686(24.8)$ & $9491(34.3)$ & $1.8(1.5 ; 2.1)$ \\
\hline Unemployed or welfare & $335(12.1)$ & $1755(6.3)$ & $4.4(3.8 ; 5.1)$ \\
\hline Early retirement & $156(5.6)$ & $771(2.8)$ & $4.3(3.5 ; 5.3)$ \\
\hline Retirement & $47(1.7)$ & $480(1.7)$ & $3.0(1.5 ; 6.0)$ \\
\hline Unknown or missing & $961(34.7)$ & $2485(9.0)$ & - \\
\hline \multicolumn{4}{|l|}{ Education } \\
\hline Higher education & $17(0.6)$ & $948(3.4)$ & 1 \\
\hline Further education & $47(1.7)$ & $3156(11.4)$ & $1.0(0.6 ; 1.8)$ \\
\hline Vocational education & $89(3.2)$ & 4623 (16.7) & $1.0(0.6 ; 1.7)$ \\
\hline Upper secondary & $51(1.8)$ & 3989 (14.4) & $1.2(0.7 ; 2.1)$ \\
\hline Primary school & $470(17.0)$ & $12,155(43.9)$ & $3.7(2.1 ; 6.3)$ \\
\hline Unknown/missing & $2096(75.7)$ & $2829(10.2)$ & - \\
\hline \multicolumn{4}{|l|}{ Ethnicity } \\
\hline Danish & $1564(56.5)$ & $23,598(85.2)$ & 1 \\
\hline Immigrant & $954(34.4)$ & $2782(10.0)$ & $5.2(4.7 ; 5.7)$ \\
\hline Descendant & $48(1.7)$ & $1058(3.8)$ & $0.7(0.5 ; 0.9)$ \\
\hline Unknown/missing & $204(7.4)$ & $262(0.9)$ & - \\
\hline \multicolumn{4}{|l|}{ Area of origin } \\
\hline Denmark & $1612(58.2)$ & $24,656(89.0)$ & 1 \\
\hline Europe & $521(18.8)$ & $1501(5.4)$ & $5.3(4.8 ; 6.0)$ \\
\hline Africa & $51(1.8)$ & $218(0.8)$ & $3.5(2.6 ; 4.8)$ \\
\hline America & $69(2.5)$ & $87(0.3)$ & $12.3(8.9 ; 16.9)$ \\
\hline Asia and Oceania & $311(11.2)$ & $970(3.5)$ & $4.9(4.3 ; 5.6)$ \\
\hline Unknown/missing & $206(7.4)$ & $268(1.0)$ & - \\
\hline \multicolumn{4}{|l|}{ Charlson comorbidity index } \\
\hline$=0$ & $2718(98.1)$ & $26,989(97.4)$ & 1 \\
\hline$\geq 1$ & $52(1.9)$ & $711(2.6)$ & $0.7(0.6 ; 1.0)$ \\
\hline
\end{tabular}

RRR adjusted for matching factors: index age and sex; RRR, relative risk ratio.

\section{Sensitivity analyses}

\section{Persons born in Denmark}

Immigrating persons are assigned a CPR number according to their sex by date of immigration. Misclassification of sex at birth would occur in the present study if a person immigrated to Denmark after sex change. We performed a sensitivity analysis where we omitted immigrants, which left 1612 persons in the dataset (1564 Danish origin and 48 descendants). The RRR of low vs high personal income was $3.7(3.2 ; 4.3)$ in transgender persons born in Denmark compared to controls and the RRR of unemployment or welfare vs employed was 7.8 (6.5; 9.4) (Supplementary Table 1, see section on supplementary materials given at the end of this article). The RRR of Charlson comorbidity index $\geq 1$ was $0.9(0.7 ; 1.3)$.

\section{Persons $>\mathbf{3 0}$ years}

Differences in SES between transgender persons and controls remained significant. The RRR for low vs high personal income was $6.8(5.4 ; 8.5)$ in transgender persons aged $>30$ years compared to age-matched controls and the RRR for unemployment or welfare vs employed was 4.9 $(3.9 ; 6.0)$ (Supplementary Table 2 ).

\section{Transgender diagnosis without legal sex change}

CPR change and foreign origin could result in more missing register data. The RRR of low vs high personal income was $3.1(2.6 ; 3.6)$ in transgender persons, who were born in Denmark and entered the study due to a diagnosis code of transgender. The number of missing data was lower in this study cohort compared to the whole study cohort of https://ec.bioscientifica.com

https://doi.org/10.1530/EC-21-0119 (c) 2021 The authors Published by Bioscientifica Ltd
This work is licensed under a Creative Commons Attribution-NonCommercial 4.0 International License. ded from Bioscientifica.com at 04/26/2023 09:59:33AM via free access 
Table 3 Socioeconomic status and Charlson comorbidity index in transgender persons AMAB $(n=1437)$ vs control males $(n=7185)$ and control females $(n=7185)$. Data presented as number (percentage). Cl 95\% adjusted for index age.

\begin{tabular}{|c|c|c|c|c|c|}
\hline & $\begin{array}{c}\text { Trans, } \\
\text { AMAB } n(\%)\end{array}$ & $\begin{array}{l}\text { Control, } \\
\text { male, } \boldsymbol{n}(\%)\end{array}$ & $\begin{array}{c}\text { Control, } \\
\text { female, } n(\%)\end{array}$ & $\begin{array}{c}\text { Trans vs control males, } \\
\text { RRR }(\mathrm{Cl} 95 \%) \text { adjusted }\end{array}$ & $\begin{array}{l}\text { Trans vs control females, } \\
\text { RRR (CI 95\%) adjusted }\end{array}$ \\
\hline \multicolumn{6}{|l|}{ Personal income } \\
\hline High & $159(11.1)$ & 2755 (38.3) & 2061 (28.7) & 1 & 1 \\
\hline Middle & $306(21.3)$ & 2145 (29.9) & 2651 (36.9) & $2.5(2.0 ; 3.0)$ & $1.5(1.2 ; 1.8)$ \\
\hline Low & $893(62.1)$ & $2278(31.7)$ & 2465 (34.3) & $6.9(5.8 ; 8.3)$ & $4.7(3.9 ; 5.6)$ \\
\hline Unknown/missing & $79(5.5)$ & $7(0.1)$ & $8(0.1)$ & - & - \\
\hline \multicolumn{6}{|l|}{ Occupational status } \\
\hline Affiliated to labour market & $349(24.3)$ & 3989 (55.5) & 3454 (48.1) & 1 & 1 \\
\hline Under education & $269(18.7)$ & $1806(25.1)$ & $2137(29.7)$ & $2.1(1.7 ; 2.6)$ & $1.3(1.1 ; 1.7)$ \\
\hline Unemployed or welfare & $207(14.4)$ & $403(5.6)$ & $552(7.7)$ & $6.0(4.9 ; 7.4)$ & $3.8(3.1 ; 4.6)$ \\
\hline Early retirement & $109(7.6)$ & $244(3.4)$ & $286(4.0)$ & $4.7(3.6 ; 6.1)$ & $3.5(2.7 ; 4.7)$ \\
\hline Retirement & $33(2.3)$ & $161(2.2)$ & $181(2.5)$ & $2.9(1.3 ; 6.4)$ & $1.7(0.7 ; 4.5)$ \\
\hline Unknown or missing & $470(32.7)$ & $582(8.1)$ & $575(8.0)$ & - & - \\
\hline \multicolumn{6}{|l|}{ Education } \\
\hline Higher education & $12(0.8)$ & $282(3.9)$ & $275(3.8)$ & 1 & 1 \\
\hline Further education & $31(2.2)$ & $706(9.8)$ & $1166(16.2)$ & $1.1(0.6 ; 2.2)$ & $0.6(0.3 ; 1.2)$ \\
\hline Vocational education & 70 (4.9) & $1659(23.1)$ & $1190(16.6)$ & $1.0(0.5 ; 1.9)$ & $1.3(0.7 ; 2.5)$ \\
\hline Upper secondary & $38(2.6)$ & $1014(14.1)$ & $1149(16.0)$ & $1.3(0.7 ; 2.6)$ & $1.0(0.5 ; 2.1)$ \\
\hline Primary school & $229(15.9)$ & $2778(38.7)$ & $2662(37.0)$ & $2.9(1.6 ; 5.5)$ & $2.6(1.4 ; 4.9)$ \\
\hline Unknown/missing & 1057 (73.6) & $746(10.4)$ & $743(10.3)$ & - & - \\
\hline \multicolumn{6}{|l|}{ Ethnicity } \\
\hline Danish & $792(55.1)$ & $6145(85.5)$ & $6166(85.8)$ & 1 & 1 \\
\hline Immigrant & $527(36.7)$ & $733(10.2)$ & $738(10.3)$ & $5.6(4.9 ; 6.4)$ & $5.6(4.9 ; 6.4)$ \\
\hline Descendant & $25(1.7)$ & $246(3.4)$ & $222(3.1)$ & $0.8(0.5 ; 1.2)$ & $0.9(0.6 ; 1.4)$ \\
\hline Unknown/missing & $93(6.5)$ & $61(0.8)$ & $59(0.8)$ & - & - \\
\hline \multicolumn{6}{|l|}{ Area of origin } \\
\hline Denmark & $817(56.9)$ & $6391(88.9)$ & $6388(88.9)$ & 1 & 1 \\
\hline Europe & $270(18.8)$ & $407(5.7)$ & $403(5.6)$ & $5.2(4.4 ; 6.2)$ & $5.3(4.4 ; 6.2)$ \\
\hline Africa & $32(2.2)$ & $68(0.9)$ & $47(0.7)$ & $3.7(2.4 ; 5.6)$ & $5.4(3.4 ; 8.5)$ \\
\hline America & $36(2.5)$ & $19(0.3)$ & $28(0.4)$ & $14.9(8.5 ; 26.1)$ & $10.2(6.2 ; 16.8)$ \\
\hline Asia and Oceania & $187(13.0)$ & $238(3.3)$ & $258(3.6)$ & $6.2(5.0 ; 7.6)$ & $5.7(4.7 ; 7.0)$ \\
\hline Unknown/missing & $95(6.6)$ & $62(0.9)$ & $61(0.8)$ & - & - \\
\hline \multicolumn{6}{|l|}{ Charlson comorbidity index } \\
\hline$=0$ & $1412(98.3)$ & 7017 (97.7) & $6945(96.7)$ & 1 & 1 \\
\hline$\geq 1$ & $25(1.7)$ & $168(2.3)$ & $240(3.3)$ & $0.7(0.5 ; 1.1)$ & $0.5(0.3 ; 0.8)$ \\
\hline
\end{tabular}

Data presented as number (percent of group). Cl 95\% adjusted for index age. AMAB, assigned male at birth; DK, Denmark; RRR, relative risk ratio.

transgender persons but still higher compared to controls (Supplementary Table 3).

\section{Transgender persons with index date before vs after 1 January 2014}

SES could be dependent on time of inclusion. Our data did not support a difference in SES in transgender persons included before vs after 2014 (Supplementary Table 4).

\section{Discussion}

In the present study, we found a high risk of lower SES in Danish transgender persons compared to age-matched controls. The RRR of low vs high personal income was 5.8 in transgender persons compared to age-matched controls and the RRR of being unemployed or on welfare vs employed was 4.4 in transgender persons. Our findings of impaired SES in transgender persons are in agreement with previous studies conducted in subgroups of transgender persons $(10,11,13)$, whereas limited data are available from national study cohorts (14). A Belgian register-based study reported that $24 \%$ of transgender persons were unemployed (14), which supported a high rate of unemployment in transgender persons, but no control group was included in the study (14). The study was conducted in 2008, which implies that legislation regarding diagnosis and treatment of gender dysphoria did not resemble the current situation in Denmark. In the present study, the median age for https://ec.bioscientifica.com

https://doi.org/10.1530/EC-21-0119 (c) 2021 The authors Published by Bioscientifica Ltd
This work is licensed under a Creative Commons Attribution-NonCommercial 4.0 International License. ded from Bioscientifica.com at 04/26/2023 09:59:33AM via free access 
Table 4 Socioeconomic status and Charlson comorbidity index in transgender persons AFAB $(n=1333)$ vs control males ( $n=6665)$ and control females $(n=6665)$. Data presented as number (percentage).

\begin{tabular}{|c|c|c|c|c|c|}
\hline & $\begin{array}{c}\text { Trans, } \\
\text { AFAB, } n(\%)\end{array}$ & $\begin{array}{l}\text { Control, } \\
\text { male, } \boldsymbol{n}(\%)\end{array}$ & $\begin{array}{c}\text { Control, } \\
\text { female, } n(\%)\end{array}$ & $\begin{array}{l}\text { Trans vs control males, } \\
\text { RRR (CI 95\%) adjusted }\end{array}$ & $\begin{array}{l}\text { Trans vs control females, } \\
\text { RRR }(\mathrm{Cl} 95 \%) \text { adjusted }\end{array}$ \\
\hline \multicolumn{6}{|l|}{ Personal income } \\
\hline High & $147(11.0)$ & $2417(36.3)$ & 1990 (29.9) & 1 & 1 \\
\hline Middle & $304(22.8)$ & 2019 (30.3) & $2410(36.2)$ & $2.5(2.0 ; 3.1)$ & $1.7(1.4 ; 2.1)$ \\
\hline Low & $779(58.4)$ & $2228(33.4)$ & 2259 (33.9) & $5.9(4.9 ; 7.1)$ & $4.7(3.9 ; 5.6)$ \\
\hline Unknown/missing & $103(7.7)$ & $\leq 5$ & $6(0.1)$ & - & - \\
\hline \multicolumn{6}{|l|}{ Occupational status } \\
\hline Affiliated to labour market & $236(17.7)$ & 2905 (43.6) & 2370 (35.6) & 1 & 1 \\
\hline Under education & $417(31.3)$ & 2590 (38.9) & $2958(44.4)$ & $2.4(1.9 ; 3.1)$ & $1.4(1.2 ; 1.8)$ \\
\hline Unemployed or welfare & $128(9.6)$ & $313(4.7)$ & $487(7.3)$ & $5.1(4.0 ; 6.5)$ & $2.6(2.1 ; 3.4)$ \\
\hline Early retirement & $47(3.5)$ & $118(1.8)$ & $123(1.8)$ & $4.7(3.2 ; 6.8)$ & $3.9(2.6 ; 5.7)$ \\
\hline Retirement & $14(1.1)$ & $66(1.0)$ & $72(1.1)$ & $4.3(1.4 ; 13.5)$ & $3.0(0.6 ; 15.1)$ \\
\hline Unknown or missing & $491(36.8)$ & $673(10.1)$ & $655(9.8)$ & - & - \\
\hline \multicolumn{6}{|l|}{ Education } \\
\hline Higher education & $5(0.4)$ & $190(2.9)$ & $201(3.0)$ & 1 & 1 \\
\hline Further education & $16(1.2)$ & $475(7.1)$ & $809(12.1)$ & $1.7(0.6 ; 5.0)$ & $0.9(0.3 ; 2.5)$ \\
\hline Vocational education & $19(1.4)$ & 1061 (15.9) & $713(10.7)$ & $0.8(0.3 ; 2.4)$ & $1.0(0.4 ; 2.8)$ \\
\hline Upper secondary & $13(1.0)$ & $866(13.0)$ & $960(14.4)$ & $1.3(0.4 ; 4.5)$ & $1.0(0.3 ; 3.4)$ \\
\hline Primary school & $241(18.1)$ & $3430(51.5)$ & $3285(49.3)$ & $5.8(1.8 ; 19.0)$ & $5.5(1.8 ; 16.5)$ \\
\hline Unknown/missing & 1039 (77.9) & $643(9.6)$ & 697 (10.5) & - & - \\
\hline \multicolumn{6}{|l|}{ Ethnicity } \\
\hline Danish & 772 (57.9) & $5669(85.1)$ & $5618(84.3)$ & 1 & 1 \\
\hline Immigrant & $427(32.0)$ & $631(9.5)$ & $680(10.2)$ & $5.1(4.4 ; 5.9)$ & $4.7(4.1 ; 5.4)$ \\
\hline Descendant & $23(1.7)$ & $300(4.5)$ & $290(4.4)$ & $0.5(0.4 ; 0.8)$ & $0.6(0.4 ; 0.9)$ \\
\hline Unknown/missing & $111(8.3)$ & $65(1.0)$ & $77(1.2)$ & - & - \\
\hline \multicolumn{6}{|l|}{ Area of origin } \\
\hline Denmark & 795 (59.6) & $5969(89.6)$ & $5908(88.6)$ & 1 & 1 \\
\hline Europe & $251(18.8)$ & $323(4.8)$ & $368(5.5)$ & $6.0(5.0 ; 7.2)$ & $5.2(4.4 ; 6.2)$ \\
\hline Africa & $19(1.4)$ & $57(0.9)$ & $46(0.7)$ & $2.6(1.5 ; 4.3)$ & $3.2(1.8 ; 5.5)$ \\
\hline America & $33(2.5)$ & $15(0.2)$ & $25(0.4)$ & $17.5(9.4 ; 32.8)$ & $10.3(6.0 ; 17.6)$ \\
\hline Asia and Oceania & $124(9.3)$ & $235(3.5)$ & $239(3.6)$ & $4.0(3.2 ; 5.1)$ & $4.0(3.2 ; 5.0)$ \\
\hline Unknown/missing & $111(8.3)$ & $66(1.0)$ & $79(1.2)$ & - & - \\
\hline \multicolumn{6}{|l|}{ Charlson comorbidity index } \\
\hline$=0$ & $1306(98.0)$ & $6521(97.8)$ & $6506(97.6)$ & 1 & 1 \\
\hline$\geq 1$ & $27(2.0)$ & $144(2.2)$ & $159(2.4)$ & $0.9(0.6 ; 1.4)$ & $0.8(0.6 ; 1.3)$ \\
\hline
\end{tabular}

RRR, relative risk ratio adjusted for index age; $\mathrm{Cl}$ 95\%, 95\% AFAB, assigned female at birth; DK, Denmark; RRR, relative risk ratio adjusted for index age.

transgender persons was 26 and 23 years (AMAB and AFAB, respectively). Transgender participants in the Belgian study were older: 42 years (MfF) and 32 years (FtM) (14), which could have affected study outcomes. More recently, a community-driven survey was conducted including 853 transgender and non-binary persons originating from five countries (Georgia, Poland, Serbia, Spain, and Sweden) (10). In total, $57.5 \%$ of participants had a general wellbeing score $<50$, which supported a high risk of poor mental health according to the WHO-5 norms (10). The study did not include a control group or data regarding affiliation to the labour market (10).

In the present study, the RRR of immigration vs Danish origin was $5.2(4.7 ; 5.7)$ in the transgender cohort, which could have affected study results regarding SES. However, our finding of lower SES in transgender persons remained significant in sensitivity analyses, where we included only persons born in Denmark and descendants. The RRR estimate of low personal income in transgender persons decreased from 5.2 to 3.7 when immigrants were excluded, which supported that transgender immigrants could be considered an especially vulnerable group regarding low SES. This is in accordance with other studies reporting that belonging to an ethnic minority group had a negative impact on general wellbeing (10) and risk of suicide (12).

The present study does not allow us to conclude regarding the reason for the high numbers of immigrants among Danish transgender persons. Denmark was one of the first countries to allow for legal sex change, which could signal a transgender-friendly environment perception. In future studies, we plan to investigate changes in the immigration pattern of transgender persons over the last

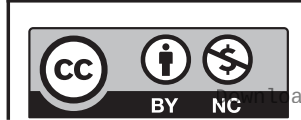


decades and possible differences in mental and physical health between transgender persons of Danish and foreign origin.

Medical morbidity is associated with lower SES, but interestingly, we found that the Charlson comorbidity index tended to be lower in transgender persons compared to controls, which would correspond to better physical health in transgender persons. These findings supported that impaired SES in transgender persons could not be explained by the presence of physical disease. Better physical health in transgender persons compared to controls may not seem a plausible study conclusion. Instead, our results could support that transgender persons, that seek professional help for transition, have better physical health than transgender persons without contact with the health care system. Gender-affirming hormonal treatment may not be prescribed in persons with severe physical disease and contraindications (1), and those persons affected may not be referred for gender-affirming hormonal treatment.

The present study cohort also included persons with CPR change only $(n=1070)$. These persons did not have a diagnosis of transgender identity in Denmark and thus no contact with a gender team. The retrospective nature of the Charlson comorbidity index could be an alternative or contributing explanation as the higher number of immigrants among transgender persons could lead to incomplete diagnosis records in the registry history, especially for persons who immigrated immediately before Charlson comorbidity index diagnosis. In accordance, the difference in morbidity between transgender persons and controls attenuated when we considered only persons born in Denmark. Population-based studies are needed to determine morbidity and SES in the whole group of transgender persons. It is possible that easier access to the health care system could increase the number of referrals of more vulnerable persons, but future studies are needed to confirm this hypothesis.

$A M A B$ and $A F A B$ persons might differ regarding SES. In the present study cohort, AMAB transgender persons tended to have more impaired SES compared to AFAB transgender persons, but this difference was not significant when we compared RRR between AMAB and $A F A B$ persons. Consequently, our data did not support the role of birth-assigned sex as a modifier for the effect of being transgender on SES. Giami recorded that French MtF transgender persons had lower education than FtM transgender persons (25). Other studies have indicated that civil status differed between transgender men and transgender women where transgender women were more likely to be married to a female and to have children before their gender reassignment $(14,25)$. These findings indicate that the needs for transgender care could differ between $\mathrm{AMAB}$ transgender persons and AFAB persons.

The long-term impact of low SES in transgender persons should be investigated in future studies. Low SES is an important predictor of health. In developed countries, lower SES with lower income $(26,27)$ and shorter education (28) is closely associated with obesity (29). Obesity increases the risk of type 2 diabetes, cardiovascular disease, and several cancer types. Furthermore, low SES was associated with a higher risk experience of health care discrimination (11) and suicidal behaviour in transgender study populations (12). The present study design will allow prospective follow-up regarding the risk of suicide and risk of medical disease according to SES in a national cohort setting.

Strengths and limitations may apply to the present study. Important strengths were the study design with nationwide data, access to well-validated register data, and the possibility to link data regarding SES on an individual basis. Some limitations may apply. The transgender diagnosis was obtained by available ICD10 codes at hospital contacts and CPR changes. Therefore, transgender persons without hospital contacts and/or with no wish for CPR change would not be included in the data set and some persons in the control group could have gender identity conditions. This could lead to underestimation of the difference in SES between transgender persons and controls.

Denmark has good access to health care, but transgender persons with off-label use of sex hormones could remain outside the dataset. Furthermore, non-binary persons could be left outside the transgender study cohort if they did not have hospital contacts for gender identity conditions and if they did not change their CPR number. Therefore, the present findings may not translate into non-binary persons. The Danish registers seemed valid concerning personal income; however, in the transgender study cohort, we observed a high percentage of missing data regarding educational status especially in persons with CPR change. These findings suggested that Danish education registers are not robust when a person changes CPR.

In Denmark, change of CPR is rarely performed, except for transgender persons. Few other circumstances allow persons to change their CPR number, such as protection of persecuted persons or criminal circumstances. These cases will not usually involve a change of the sex identifier of the CPR number. Future register-based studies should pay attention to the possible limitations of national registers when persons change their CPR. We divided persons

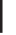

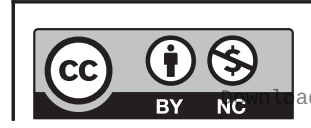


according to assigned gender at birth, which could lead to misclassification of sex in foreigners if they immigrated after the date of the legal sex-change. Therefore, we performed a sensitivity analysis in persons born in Denmark. In future studies, the use of feminizing or masculinizing hormonal treatment could be applied as an additional criterion to define transgender women and transgender men in those born outside Denmark. The register-based design of the present study did not allow us to conclude on the reason for the high number of immigrants in Danish transgender persons.

\section{Conclusion}

Socioeconomic status was lower in Danish transgender persons compared to controls. Immigrants constituted a substantial part of transgender persons in Denmark. Our data supported that transgender persons of foreign origin need special attention regarding low socioeconomic status.

\section{Supplementary materials}

This is linked to the online version of the paper at https://doi.org/10.1530/ EC-21-0119.

\section{Declaration of interest}

The authors declare that there is no conflict of interest that could be perceived as prejudicing the impartiality of the research reported.

\section{Funding}

The collaboration fund between Odense University Hospital and Rigshospitalet, 2019.

\section{References}

1 T’Sjoen G, Arcelus J, Gooren L, Klink DT \& Tangpricha V. Endocrinology of transgender medicine. Endocrine Reviews 201940 97-117. (https://doi.org/10.1210/er.2018-00011)

2 Motmans J, Meier P, Ponnet K \& T'Sjoen G. Female and male transgender quality of life: socioeconomic and medical differences. Journal of Sexual Medicine 20129 743-750. (https://doi.org/10.1111/ j.1743-6109.2011.02569.x)

3 Schulman JK \& Erickson-Schroth L. Mental health in sexual minority and transgender women. Medical Clinics of North America 2019103 723-733. (https://doi.org/10.1016/j.mcna.2019.02.005)

4 Witcomb GL, Bouman WP, Claes L, Brewin N, Crawford JR \& Arcelus J. Levels of depression in transgender people and its predictors: results of a large matched control study with transgender people accessing clinical services. Journal of Affective Disorders 2018235 308-315. (https://doi.org/10.1016/j.jad.2018.02.051)

5 Chen R, Zhu X, Wright L, Drescher J, Gao Y, Wu L, Ying X, Qi J, Chen C, Xi Y, et al. Suicidal ideation and attempted suicide amongst Chinese transgender persons: national population study. Journal of Affective Disorders 2019245 1126-1134. (https://doi.org/10.1016/j. jad.2018.12.011)
6 Tan KKH, Treharne GJ, Ellis SJ, Schmidt JM \& Veale JF. Gender minority stress: a critical review. Journal of Homosexuality 202067 1471-1489. (https://doi.org/10.1080/00918369.2019.1591789)

7 Lazarus JV, Baker L, Cascio M, Onyango D, Schatz E, Smith AC, Spinnewijn F \& Nobody Left Outside Initiative. Novel health systems service design checklist to improve healthcare access for marginalised, underserved communities in Europe. BMJ Open 202010 e035621. (https://doi.org/10.1136/bmjopen-2019-035621)

8 Stringhini S, Carmeli C, Jokela M, Avendaño M, Muennig P, Guida F Ricceri F, d'Errico A, Barros H, Bochud M, et al. Socioeconomic status and the $25 \times 25$ risk factors as determinants of premature mortality: a multicohort study and meta-analysis of 1.7 million men and women. Lancet 2017389 1229-1237. (https://doi.org/10.1016/S01406736(16)32380-7)

9 Varbanova V \& Beutels P. Recent quantitative research on determinants of health in high income countries: a scoping review. PLoS ONE 2020 15 e0239031. (https://doi.org/10.1371/journal.pone.0239031)

10 Burgwal A, Gvianishvili N, Hård V, Kata J, García Nieto I, Orre C, Smiley A, Vidić J \& Motmans J. Health disparities between binary and non binary trans people: a community-driven survey. International Journal of Transgenderism 201920 218-229. (https://doi.org/10.1080/15 532739.2019.1629370)

11 Shires DA \& Jaffee K. Factors associated with health care discrimination experiences among a national sample of female-tomale transgender individuals. Health and Social Work 201540 134-141. (https://doi.org/10.1093/hsw/hlv025)

12 Adams NJ \& Vincent B. Suicidal thoughts and behaviors among transgender adults in relation to education, ethnicity, and income: a systematic review. Transgender Health 20194 226-246. (https://doi. org/10.1089/trgh.2019.0009)

13 Bauermeister JA, Goldenberg T, Connochie D, Jadwin-Cakmak L \& Stephenson R. Psychosocial disparities Among racial/ethnic minority transgender young adults and young men who have sex with men living in detroit. Transgender Health 20161 279-290. (https://doi. org/10.1089/trgh.2016.0027)

14 Motmans J, Ponnet K \& De Cuypere G. Sociodemographic characteristics of trans persons in Belgium: a secondary data analysis of medical, state, and social data. Archives of Sexual Behavior 201544 1289-1299. (https://doi.org/10.1007/s10508-014-0411-2)

15 Zhang Q, Goodman M, Adams N, Corneil T, Hashemi L, Kreukels B, Motmans J, Snyder R \& Coleman E. Epidemiological considerations in transgender health: a systematic review with focus on higher quality data. International Journal of Transgender Health 202021 125-137. (https://doi.org/10.1080/26895269.2020.1753136)

16 Schmidt M, Schmidt SA, Sandegaard JL, Ehrenstein V, Pedersen L \& Sorensen HT. The Danish National Patient Registry. The Danish National Patient Registry: a review of content, data quality, and research potential. Clinical Epidemiology 20157 449-490. (https://doi. org/10.2147/CLEP.S91125)

17 Schmidt M, Pedersen L \& Sørensen HT. The Danish Civil Registration System as a tool in epidemiology. European Journal of Epidemiology 2014 29 541-549. (https://doi.org/10.1007/s10654-014-9930-3)

18 Schmidt M, Schmidt SAJ, Adelborg K, Sundbøll J, Laugesen K, Ehrenstein V \& Sørensen HT. The Danish Health Care System and Epidemiological Research: from health care contacts to database records. Clinical Epidemiology 201911 563-591. (https://doi. org/10.2147/CLEP.S179083)

19 Reed GM, Drescher J, Krueger RB, Atalla E, Cochran SD, First MB, Cohen-Kettenis PT, Arango-de Montis I, Parish SJ, Cottler S, et al. Disorders related to sexuality and gender identity in the ICD-11: revising the ICD-10 classification based on current scientific evidence, best clinical practices, and human rights considerations. World Psychiatry 201615 205-221. (https://doi.org/10.1002/wps.20354)

20 Baadsgaard M \& Quitzau J. Danish registers on personal income and transfer payments. Scandinavian Journal of Public Health 201139 103-105. (https://doi.org/10.1177/1403494811405098)

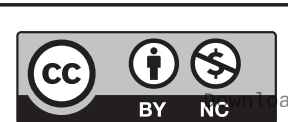

This work is licensed under a Creative Commons Attribution-NonCommercial 4.0 International License. ded from Bioscientifica.com at 04/26/2023 09:59:33AM 
21 Jensen VM \& Rasmussen AW. Danish education registers. Scandinavian Journal of Public Health 201139 91-94. (https://doi. org/10.1177/1403494810394715)

22 Pedersen CB. The Danish civil registration system. Scandinavian Journal of Public Health 201139 22-25. (https://doi. org/10.1177/1403494810387965).

23 Charlson ME, Pompei P, Ales KL \& MacKenzie CR. A new method of classifying prognostic comorbidity in longitudinal studies: development and validation. Journal of Chronic Diseases 198740 373-383. (https://doi.org/10.1016/0021-9681(87)90171-8)

24 Quan H, Sundararajan V, Halfon P, Fong A, Burnand B, Luthi JC, Saunders LD, Beck CA, Feasby TE \& Ghali WA. Coding algorithms for defining comorbidities in ICD-9-CM and ICD-10 administrative data. Medical Care 200543 1130-1139. (https://doi.org/10.1097/01. mlr.0000182534.19832.83)

25 Giami A \& Beaubatie E. Gender identification and sex reassignment surgery in the trans population: a survey study in France. Archives of
Sexual Behavior 201443 1491-1501. (https://doi.org/10.1007/s10508 014-0382-3)

26 Wamala SP, Wolk A \& Orth-Gomer K. Determinants of obesity in relation to socioeconomic status among middle-aged Swedish women. Preventive Medicine 199726 734-744. (https://doi.org/10.1006/pmed.1997.0199)

27 Delva J, Johnston LD \& O’Malley PM. The epidemiology of overweight and related lifestyle behaviors: racial/ethnic and socioeconomic status differences among American youth. American Journal of Preventive Medicine 200733 S178-S186. (https://doi.org/10.1016/j. amepre.2007.07.008)

28 Sabanayagam C, Shankar A, Wong TY, Saw SM \& Foster PJ Socioeconomic status and overweight/obesity in an adult Chinese population in Singapore. Journal of Epidemiology 200717 161-168. (https://doi.org/10.2188/jea.17.161)

29 Newton S, Braithwaite D \& Akinyemiju TF. Socio-economic status over the life course and obesity: systematic review and meta-analysis. PLoS ONE 201712 e0177151. (https://doi.org/10.1371/journal.pone.0177151)

Received in final form 4 July 2021

Accepted 17 August 2021

Accepted Manuscript published online 19 August 2021
This work is licensed under a Creative Commons Attribution-NonCommercial 4.0 International License. ded from Bioscientifica.com at 04/26/2023 09:59:33AM via free access 